\title{
GOIÂNIA: MODERNISMO PERIFÉRICO
}

\section{GOIÂNIA: PERIPHERICAL MODERNISM}

\author{
Anamaria Diniz 1
}

Doutora em Arquitetura e Urbanismo pela Universidade de Brasília - UnB (2015). Pesquisadora Fonds Historiques do Institut d'Urbanisme de Paris - IUP/UPEC (2011-2015). Estágio doutoral em História pela Universidade Federal de Goiás - UFG em "História Urbana".

\begin{abstract}
RESUMO
Os projetos urbanísticos de Attilio Corrêa Lima elaborados para Goiânia, no período de 1932 a 1935, são objeto de análise nos seus aspectos morfológicos, simbólicos e da sua evolução urbana a partir de fontes primárias. Attilio C. Lima idealizou uma cidade moderna sobre uma tábula rasa, influenciado pelos paradigmas da escola francesa de urbanismo, o Institut d'Urbanisme de Paris (IUUP). Entre a capital planejada, materializada e modificada há lacunas a serem investigadas esclarecendo as diversas camadas construídas. Corrêa Lima realizou não só os projetos urbanísticos para a nova capital de Goiás, como também o primeiro plano diretor da cidade. As leituras de fontes primárias, dos planos originais, documentos e de imagens permitem o resgate de um período da história da implantação da cidade de Goiânia envolta em mitos e contradições.
\end{abstract}

Palavras-chave: Goiânia. Attilio Corrêa Lima; Paisagem urbana; Modernismo; Urbanismo.

\begin{abstract}
Attilio Corrêa Lima's Goiânia urban projects, from 1932 to 1935, are analyzed in their morphological aspects, simbolics and their urban evolution from primary sources. Attilio C. Lima devised a modern city on a tabula rasa, influenced by the paradigms of the French school of urbanism, the Institut d'Urbanisme de Paris (IUUP). Between the planned, materialized and modified capital there are gaps to be investigated by clarifying the various layers constructed. Corrêa Lima did not only the urban projects for the new capital of Goiás, but also the first master plan of the city. The readings of the plants, the documents and the images allow the rescue of a period of the history Goiania implantation city, shrouded in myths and contradictions.
\end{abstract}

Keywords: Goiânia; Attilio Corrêa Lima; Urban landscape; Modernism; Urbanism.

\section{Comissão e encenação: a escolha do lugar}

Durante as pesquisas de mestrado e doutorado", por mais de dez anos, projetos, documentos, fotografias e vários outros registros do acervo da família Corrêa Lima $^{2}$ foram analisados. O contato com fontes primárias, os planos elaborados pelo urbanista

${ }^{1}$ Dissertação de mestrado: Goiânia de Attilio Corrêa Lima (19321935): ideal estético e realidade política (UnB-2007). Tese de doutorado: O itinerário pioneiro do urbanista Attilio Corrêa Lima (UnB/IUP-UPEC 2015).

${ }^{2} \mathrm{~A}$ família Corrêa Lima, representada pelo filho de Attilio Corrêa Lima (1901-1943), o também arquiteto Bruno Corrêa Lima e a sua neta, a museóloga Rachel Corrêa Lima, mantém na cidade de Nova Friburgo, na região serrana do Rio de Janeiro, um museu particular com a produção arquitetônica e urbanística referentes ao período em que o arquitetourbanista exerceu suas atividades acadêmicas e profissionais.
Attilio Corrêa Lima para a nova capital de Goiás, Goiânia, em papel vegetal, desenhados a nanquim ou mesmo a lápis, os primeiros croquis, os esboços, são registros de leitura inesgotáveis.

A proximidade com o acervo e com a própria família Corrêa Lima contribuíram para aumentar o interesse pelo arquiteto urbanista, por sua formação, e, assim, fomentar o desejo de "descobrir" fatos ocorridos na época do desenvolvimento dos projetos para Goiânia. Consequentemente estabeleceu-se vínculos de confiança com os Corrêa Lima, permitindo o acesso livre a um acervo rico e precioso. Essa farta documentação é de grande relevância para o urbanismo brasileiro. Nela se encontram croquis, correspondências, projetos executivos, textos e memoriais, trabalhos acadêmicos 
realizados no curso de arquitetura na Escola Nacional de Belas Artes, a ENBA (1920 a 1925), e de outros, quando Attilio C. Lima cursou urbanismo no Institut d'Urbanisme de l'Université de Paris (IUUP), durante os anos de 1927 a 1930. Portanto, esses registros representam um tesouro para os estudiosos interessados em entender a formação do campo do urbanismo no Brasil, além daquela do arquiteto e de suas atividades na primeira metade do século XX.

A cada olhar sobre as imagens dos planos de Goiânia, confrontando textos e documentos, é possível montar um "quebra-cabeça", revelando e compreendendo as soluções urbanísticas e arquitetônicas tomadas por Attilio C. Lima, ou mesmo formulando novos questionamentos sobre os primeiros anos da construção da nova capital.

No início do ano de 1932, Attilio C. Lima recebeu o convite de Pedro Ludovico para desenvolver os projetos e supervisionar as obras de implantação da nova capital do estado de Goiás, sendo o objeto de contrato: a organização do traçado da cidade, os projetos de infraestrutura, plano diretor, os projetos arquitetônicos dos principais edifícios públicos e casas para funcionários, além da estruturação administrativa.

A escolha da região de Campinas como sítio para a implantação da nova capital de Goiás, foi definida pelo interventor Pedro Ludovico antes mesmo do relatório final da comissão técnica de 1933. Contrariando a "história oficial", Attilio C. Lima já trabalhava na região em 1932, como é possível comprovar através da foto para o Plano Diretor de 1935 (FIGURA 1), na qual o urbanista encontra-se no meio do Cerrado com seus ajudantes. Nas anotações à lápis, como observações e o carimbo do Serviço Gráfico do IBGE, leia-se: "1932 - A fixação do lugar da cidade. O Engo. Attilio Corrêa Lima escolhe o ponto onde deve bater a estaca 0",

A foto com as anotações à lápis revela principalmente que o urbanista realizava levantamentos em campo, localizando e implantando o projeto da cidade, antes mesmo do resultado da "escolha do lugar" pela comissão técnica escolhida pelo interventor Pedro Ludovico.

Não só através das imagens e fotos encontradas no acervo da família Corrêa Lima confirma-se que Attilio C. Lima já realizava os primeiros estudos da cidade próximo a Campinas, como também na pesquisa de Mendonça (2009), o autor apresenta os decretos e entrevistas da época apontando a "encenação política" criada pelo interventor. No decreto no. 2.737 de dezembro de 1932, Pedro Ludovico Teixeira designou "uma comissão de oito pessoas com o objetivo de escolher ou adaptar o melhor lugar para se edificar a nova capital" (MENDONÇA, 2009). Os integrantes dessa comissão eram pessoas de destaque político da sociedade, como o bispo de Goiás, Dom Emanuel Gomes de Oliveira; os engenheiros João

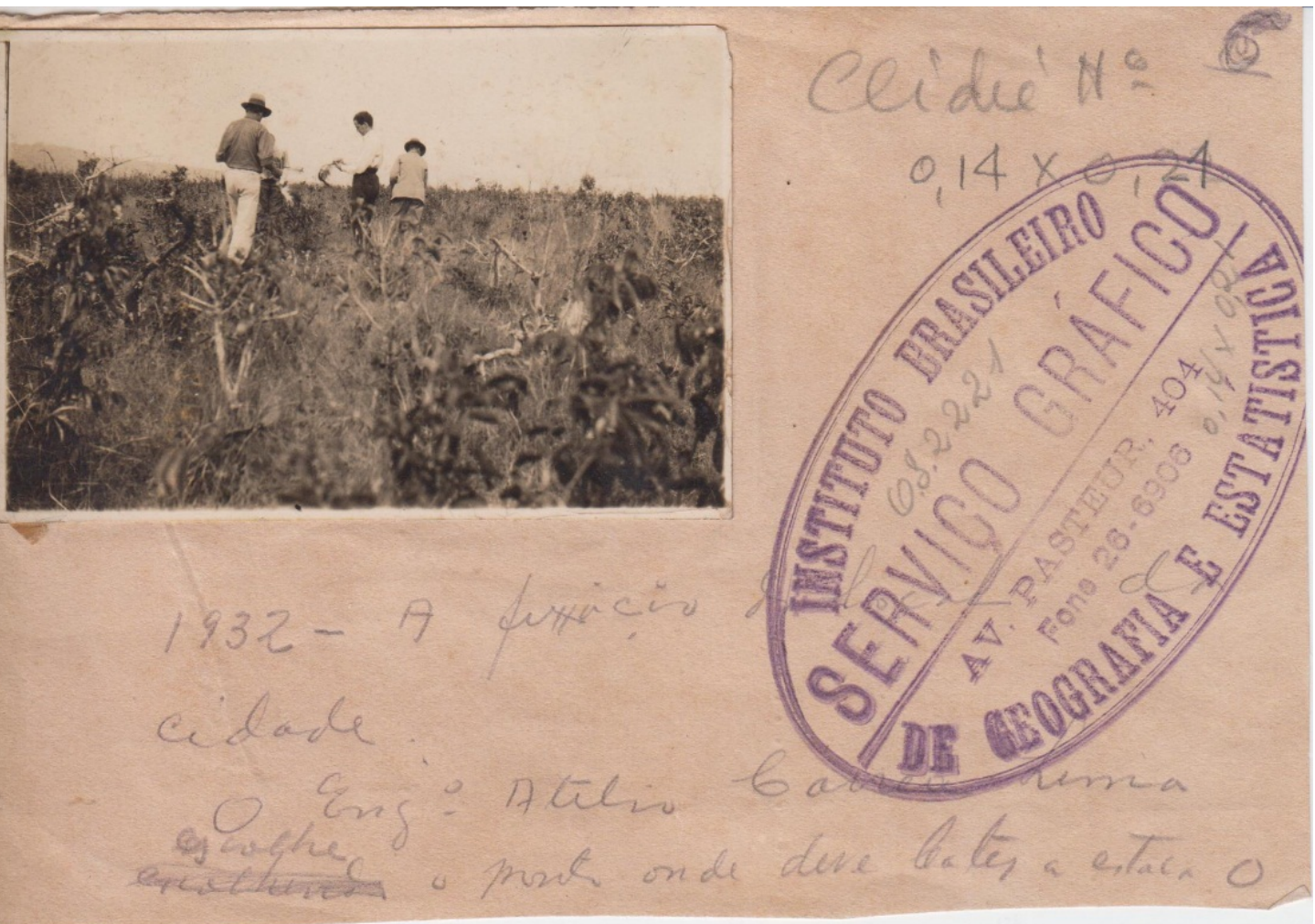

\section{FIGURA 1}

Attilio Corrêa Lima fixando o lugar da nova capital. Fonte: Acervo da família Corrêa Lima. Foto: Lúcio Malagoni Cardoso. 
Argenta e Jerônimo Curado Fleury; o professor e jurista Colemar Natal e Silva; o médico-higienista Laudelino Gomes de Almeida; o coronel Antônio Pirineus de Sousa e os comerciantes Antônio Augusto Santana e Gumercindo Alves Ferreira. Apesar do peso político e da influência da igreja católica, na figura de Dom Emanuel que era a favor da escolha da cidade de Bonfim, atual Silvania, para receber a implantação da nova capital, segundo Mendonça (2009), o interventor contava com a maioria dos votos a seu favor.

Em janeiro de 1933, a comissão reuniu-se em Bonfim, sendo escolhido para presidi-la o arcebispo de Goiás, D. Emanuel Gomes de Oliveira, que na ocasião afirmou que se sentia honrando com a indicação, no entanto lamentava que a transferência da capital do Estado de Goiás para um outro sítio "fosse mal compreendido por parte da laboriosa população da Capital", mas que acreditava que no futuro seria "grandemente beneficiada com a mudança que visa não só maior prosperidade para o Estado como melhores condições e conforto e progresso para os habitantes da antiga Capital" (MONTEIRO, 1938, p. 33).

Um dos integrantes da comissão, o jurista Colemar Natal e Silva apontou as dificuldades de locomoção e as condições das estradas para percorrer todo Estado e analisar tecnicamente o melhor sítio para receber a nova capital. Assim foram traçadas quatro condições básicas para atender a possibilidade de escolha do lugar como: recursos hidrícos, a proximidades da estrada de ferro, bom clima e topografia adequada. Dentre várias cidades, as que respondiam esses quisitos e indicadas na reunião da comissãose estavam: Bonfim, Pires do Rio, Ubatan e Campinas.

Para Mendonça (2009) houve uma "encenação governamental" e, enquanto a comissão da escolha do lugar ocupava-se com as visitas e análises, “Campinas já estava escolhida antes mesmo da instalação da comissão". Pedro Ludovico, segundo o autor, concedeu uma entrevista "treze dias antes da designação dos oitos membros do grupo", emergindo a veemente defesa campineira", com as seguintes afirmações:

Por enquanto não se fixou nenhum logar para esse fim. Goiás tem logares magnificos para a construção de uma capital. Entre outros, posso citar, desde já, o município de Campinas. Há ali um local admirável, recortado pelo rio Meia Ponte, com grande abundancia de agua, com uma cachoeira com a potencialidade de 1.500 cavalos, situada a 3 quilometros de distancia e com a altitude media de 800 metros acima do nível do mar. O local é saluberrimo, tendo, ainda, a vantagem de ser um centro de irradiação, ligado por meio de estradas amplamente trafegadas, a 8 municipios da maior importancia no concerto goiano. Esta situado a 150 quilometros da atual capital e a 60 quilometros do ponto terminal da Estrada de Ferro Goiás. (MENDONÇA, 2009, p. 180)
Pedro Ludovico ao escolher a região de Campinas para transferir a nova capital, num jogo de cena, parecendo ser democrático instituindo uma comissão para determinar o lugar, agiu de forma autoritária, deixando claro que não queria viver à sombra do poder da igreja e do bispo Dom Emanuel, que exercia uma posição de liderança da cidade de Bonfim e era apoiado pela oligarquia Caiadista. Por outro lado, “Dom Emanuel também não aceitou viver sob o poder de Pedro Ludovico e não transferiu a sede da arquidiocese para Goiânia" (BORGES, 2007).

\section{O lugar: triângulo emoldurado}

\section{A subcomissão técnica formada por três engenheiros para a mudança da capital indicou as Paineiras como local para implantar a área central da cidade, porém o urbanista discordou justificando:}

“[...] o local denominado Paineira para o assentamento do núcleo inicial, discordamos dessa opinião por ser o local muito deslocado da estrada de rodagem. Sendo a estrada a artéria vivificadora do organismo urbano, tudo indicava que o núcleo central devia ser atravessado por aquela". (LIMA, 1937)

Corrêa Lima projetou o núcleo central mais próximo da estrada de rodagem que fazia a ligação entre Campinas, cidade que deu apoio à construção de Goiânia, e Leopoldo de Bulhões, aonde chegava a ferrovia. (FIGURA 2)

O primeiro esboço da cidade é a definição "do lugar", no qual Attilio Corrêa Lima traçou a figura geométrica do triângulo equilátero, simbolizando como o sítio da nova capital. O urbanista delimitou o território a ser ocupado através dos principais córregos, preocupandose em ligar a cidade às outras regiões do país através de um aeródromo. O croqui encontrado foi desenhado à lápis sobre papel manteiga, na escala de 1:5.000, conforme pode-se verificar na figura 2.

Esse registro tem um suporte muito frágil, o papel manteiga, além dos traços em grafite que ao longo de anos estão desaparecendo. Para melhorar a leitura e as análises, foram desenhados traços sobre a matriz original de Attilio C. Lima (FIGURA 3).

O núcleo inicial da nova capital (em amarelo) é representado por um triângulo, emoldurado pelos Córregos Botafogo e Capim-Puba (em azul). O vértice principal do triângulo, Attilio C. Lima denominou-o como "Centro Cívico", enquanto que na sua base localizou o Centro Comercial. A antiga estrada de rodagem (em vermelho) que ligava as cidades de Leopoldo de Bulhões e Campinas teve seu traçado parcialmente deslocado para atender as duas pistas de pouso do aeródromo, 


\title{
FIGURA 3
}

\author{
Attilio Corrêa Lima \\ fixando o lugar da \\ nova capital. \\ Fonte: acervo da \\ família Corrêa Lima. \\ Foto: Lúcio Malagoni \\ Cardoso.
}

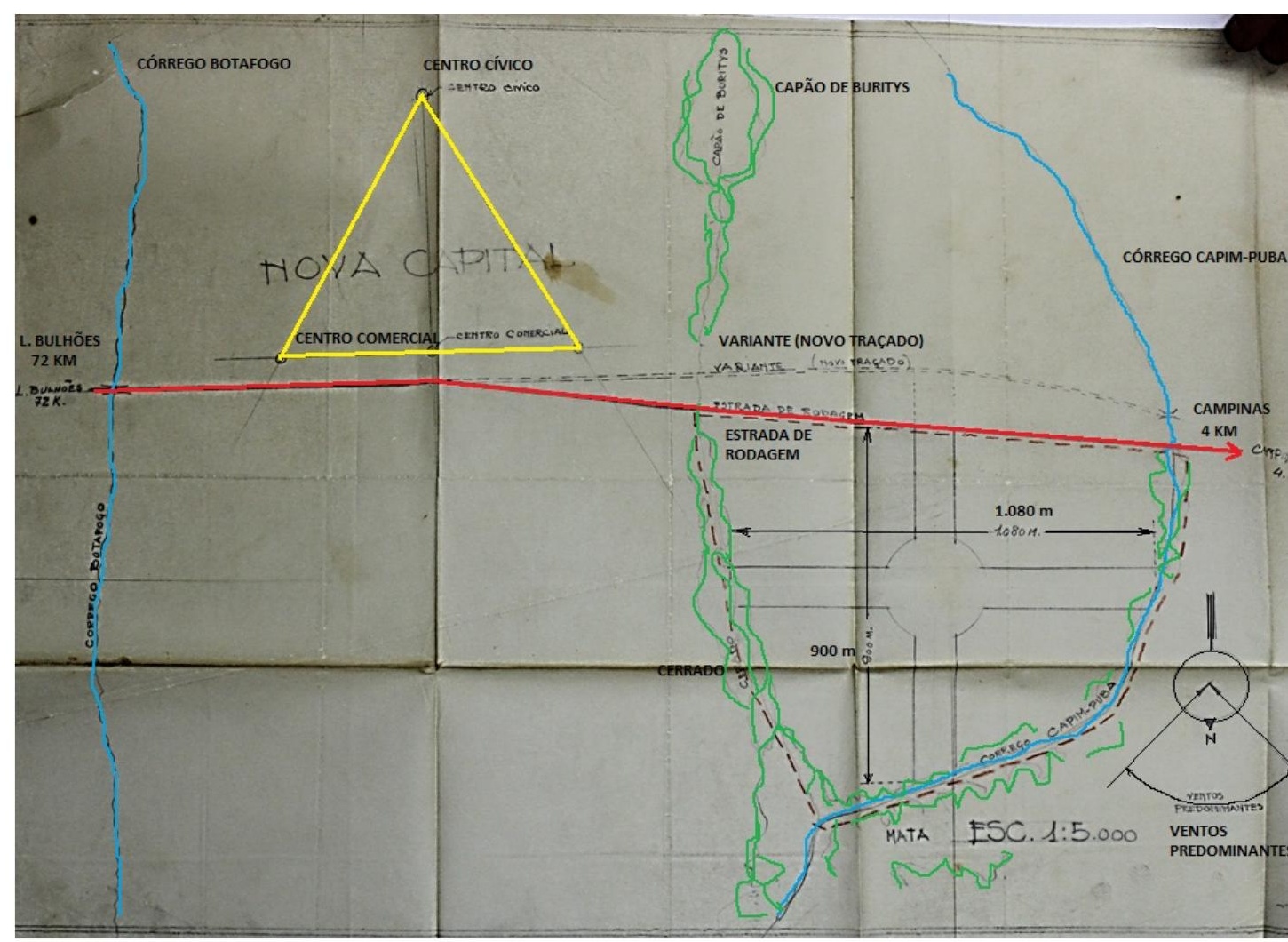

\section{Modernismo periférico}

[...] Esforço de atualização visando à auto-afirmação: eis um dos limites da condição moderna na periferia. O outro é a própria experiência da modernidade. Ritmos, formas, relações com a natureza e vida mental são alterados pela vertigem fantasmagórica, ou seja, as sensações provocadas pelos processos sociais que agem no capitalismo: individualismo, autonomização, desencantamento, alienação, inovação, efemeridade, destruição criativa, especialização, fragmentação, disciplinarização. (SILVA, 1997, p. 107)

A orientação "Norte" para baixo desenhada em todos os mapas da nova capital de Goiás pelo arquiteto-urbanista Attilio Corrêa Lima, não só é uma transgressão de convenções, como também uma posição nacionalista frente a visão eurocêntrica do mundo.

O eurocentrismo pode ser visto como o imaginário dominante do sistema do mundo moderno - um conjunto de categorias e imagens de mundo adaptável às alterações na organização do poder global, mas sempre emitido a partir de um ponto de vista do centro europeu/ocidental desse sistema. Nesse sentido, o eurocentrismo também pode ser apresentado "como a naturalização da sociedade liberal europeia como a única possível ou desejável" (BORTOLUCI, 2009; LANDER, 2005).
A separação fundadora do pensamento político ocidental moderno, entre homem (razão) e mundo é uma das consequências da naturalização da sociedade liberal, buscando o "conhecimento descorporeizado e descontextualizado, objetivo e universal", ligado "a uma noção de progresso, desenvolvida em um contexto de assimetria de poder global" (BORTOLUCI, 2009).

A modernidade a partir do discurso eurocêntrico, como dispositivo de conhecimento universal, hierarquizando as diversas experiências humanas, determina as outras formas de viver negativamente, como formas incompletas, e não como outras formas particulares de completude (LANDER, 2005).

Attilio Corrêa Lima, homem e urbanista de seu tempo, comungava com o pensamento modernista do esprit nouveau, que acreditava que, através da arquitetura e do urbanismo moderno, um novo homem nasceria na cidade planejada sobre uma tábula rasa, no meio do sertão brasileiro. Goiânia como a ilha de Utopia nasceria da vontade de seu idealizador, de transformação de uma nova sociedade, longe das oligarquias e da corrupção da antiga capital- Goiás Velho.

Apesar de seu nacionalismo, Corrêa Lima foi buscar na sua formação francesa em urbanismo, exemplos urbanísticos que espelhassem o desejo do interventor 


\section{FIGURA 5}

Projeto urbanístico de

Goiânia de Attilio

Corrêa Lima,

destacando as

principais avenidas e a

Praça Cívica - 1932.

Fonte: acervo da

família Corrêa Lima.

Foto: Lúcio Malagoni

Cardoso.

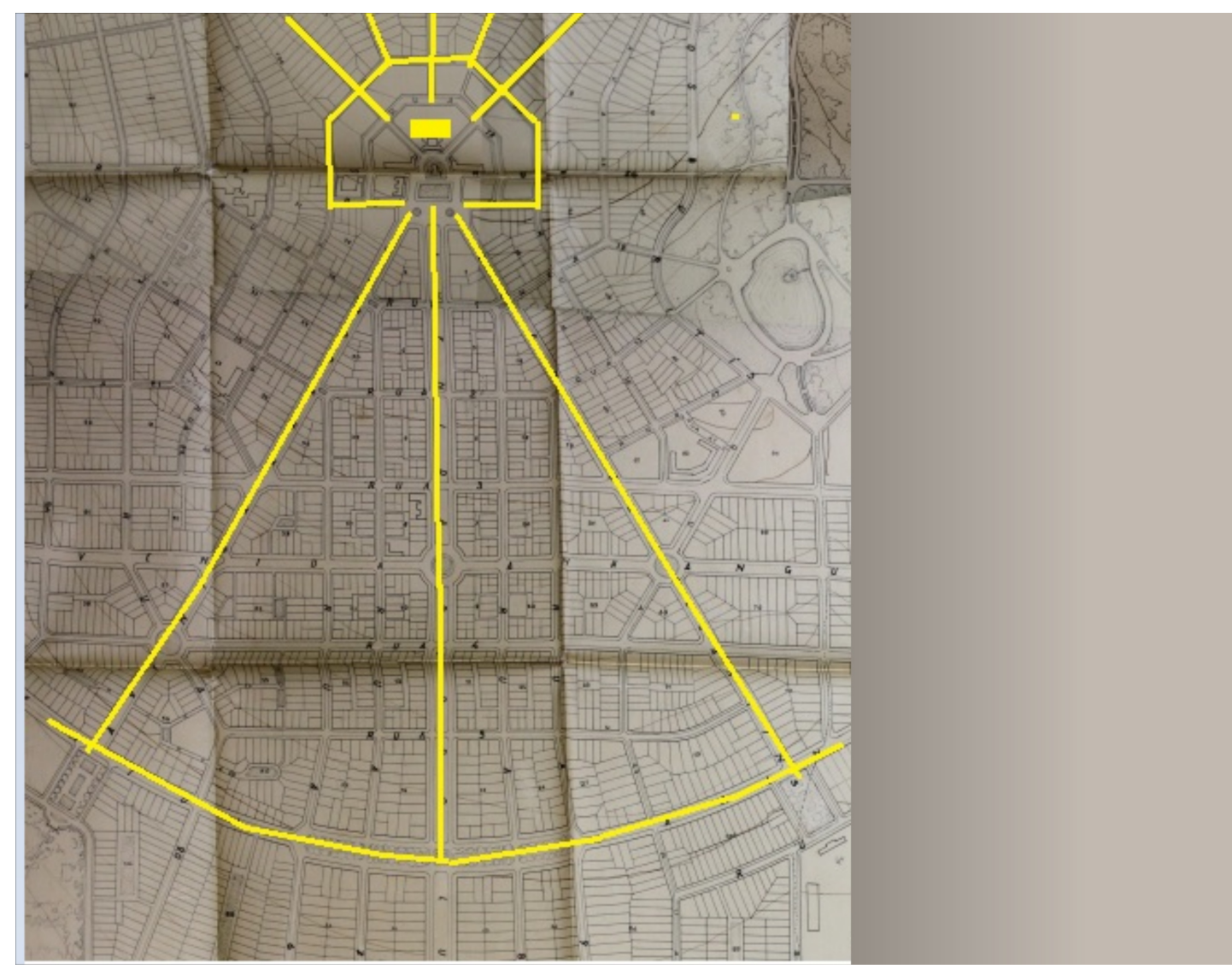

\section{Nova Goyaz - a cidade aeroporto}

\begin{abstract}
Attilio C. Lima ampliou as plantas do aeródromo (FIGURA 6), detalhando-as em duas pistas perpendiculares, com 100 metros de largura e 1.000 metros de extensão, no canto esquerdo superior, indicou também a distância de $\mathbf{1 . 0 0 0}$ metros em relação ao Centro da Cidade, exatamente no encontro da estrada de rodagem e a futura Avenida Tocantins.
\end{abstract}

O urbanista nomeou o aeródromo como Nova Goyaz, assim o núcleo inicial, "o lugar", confunde-se com o aeródromo, as pistas de pouso que recebiam aqueles que chegavam e partiam da nova capital.

${ }^{4}$ Arquitetura e Urbanismo - março e abril de 1937 - Goiânia a nova capital de Goiás - Resumo de um Estudo.

${ }^{5}$ Amílcar Sérgio Veloso Pederneiras (1894-1950), ingressou na Escola Militar do Realengo em 1914. Em julho de 1924 atuou como observador aéreo nas operações destinadas a apoiar as tropas que combatiam os revoltosos de São Paulo. Esse movimento, conhecido como o Segundo 5 de Julho, inseriu-se no conjunto de revoltas tenentistas da década de 1920. Com a criação do Ministério da Aeronáutica em janeiro de 1941, transferiu-se para a nova força e ocupou, já na patente de coronel-aviador, o cargo de diretor de Aeronáutica Militar de fevereiro de 1941 até janeiro do ano sequinte. Neste último mês, no posto de brigadeiro-do-ar, assumiu o comando da III Zona Aérea, no Rio de Janeiro. Em abril de 1942 foi nomeado por Getúlio Vargas ministro do Superior - então Supremo Tribunal Militar (STM). Fontes: CORRESP. SUP. TRIB. MILITAR.
Destaca-se a importância da construção de um aeródromo muito próximo à área central, proporcionalmente, até meados dos anos 50, tinha a extensão da área urbana da capital e, de certa forma, o avião era o único meio de transporte que a ligava às outras regiões do país, uma vez que a ferrovia chegou tardiamente, e a malha rodoviária era incipiente no Centro-Oeste.

Attilio C. Lima após a entrega dos planos da cidade relatou em artigo para uma revista ${ }^{4}$ sua confiança no papel que teria a implantação de um aeródromo na nova capital:

[...] O Aeródromo, foi por nós projetado e construído, quando ainda havia descrença na possibilidade da ida de aviões ao local. Confiantes no papel que cabe à aviação, principalmente para as longas distâncias e acesso difícil, e, conhecendo a deficiência dos campos de pouso existentes no Estado, empreendemos a construção, relativamente simples, dadas as condições do terreno. Consta o campo de duas pistas que cruzam norte-sul e este-oeste, aproximadamente com 100 metros de largura e 1.000 de extensão. (LIMA, 1937)

O urbanista exaltou a importância da construção do aeródromo de Goiânia, destacando a sua segurança e qualidade de construção, além do pioneirismo da ligação com outros centros do país através da linha do correio aéreo militar levada pelo Coronel Amilcar Pederneiras ${ }^{5}$ : 
[...] A boa impressão causada ao Coronel Amílcar Pederneiras, quando por lá passou, valeu-nos uma certa confiança, pois nunca esquecemos dos ares de mofa com que foi encarado o início da construção do campo pelos derrotistas. O Aeródromo de Goiânia foi ao encontro das necessidades mesmo da aviação e é hoje, pode-se dizer, o melhor campo do Estado, pela segurança que inspira. O ilustre militar a quem acima nos referimos, conseguiu pouco depois, modificar a rota da linha do correio aéreo militar, verdadeiro pioneiro do progresso dos nossos sertões, fazendo-a pousar semanalmente em Goiânia. (LIMA, 1937)

As experiências vividas por Attilio C. Lima durante os anos em que morou em Paris e que antecederam os planos de Goiânia, influenciaram em suas decisões de como planejar uma cidade sobre uma tábula rasa no sertão. Para completar sua bolsa de estudos do IUUP, o urbanista trabalhou na missão militar brasileira na França, que segundo Bellintani (2009), desde janeiro de 1927, quando foi "[...] criada a arma de aviação no Exército Brasileiro" abriu crédito para a compra de material de 115 milhões de francos, "a serem gastos em cinco anos, no programa de organização da aviação". Essa experiência inusitada para um arquiteto, Attilio C. Lima descreveu em uma das cartas enviada ao seu pai:
Paris, 13 de abril de 1929.

Queridos pais,

[...] Arranjei um emprego na missão militar em que ganho 1500 francos por mês e trabalho só de manhã. “Eu já estou virando uma enciclopédia". Imagine que agora é com a mecânica!! Urbanismo, arquitetura, filosofia, ciências econômicas, motores de aviação etc.

Imagine que tenho o pomposo título de "Contrôleur" e nada mais é que um "perito" (um perito! em língua indígena) da missão brasileira, que verifica e submete a exame todas as peças de um motor, e aceita ou rejeita conforme for. Esse trabalho não exige conhecimentos técnicos do assunto, é preciso somente com que se conheça desenho e praticar com delicadíssimos aparelhos micrométricos para verificar as peças. Esse trabalho em um dia se aprende. Como a missão tem a incumbência de comprar motores em diversas fábricas, é preciso que tenha um Contrôleur para cada uma. [...] numa semana já controlei algumas milhares de peças que compõe dois possantes motores de 500 cavalos cada um. Esses motores são para um avião do exército! Que contra senso! Motores para o exército! Enquanto que Mato Grosso continua inexplorado! Ele daria um bom avião de transporte para 20 passageiros, imagine que o avião tem dois motores e que cada motor custa simplesmente 180 mil francos [...].

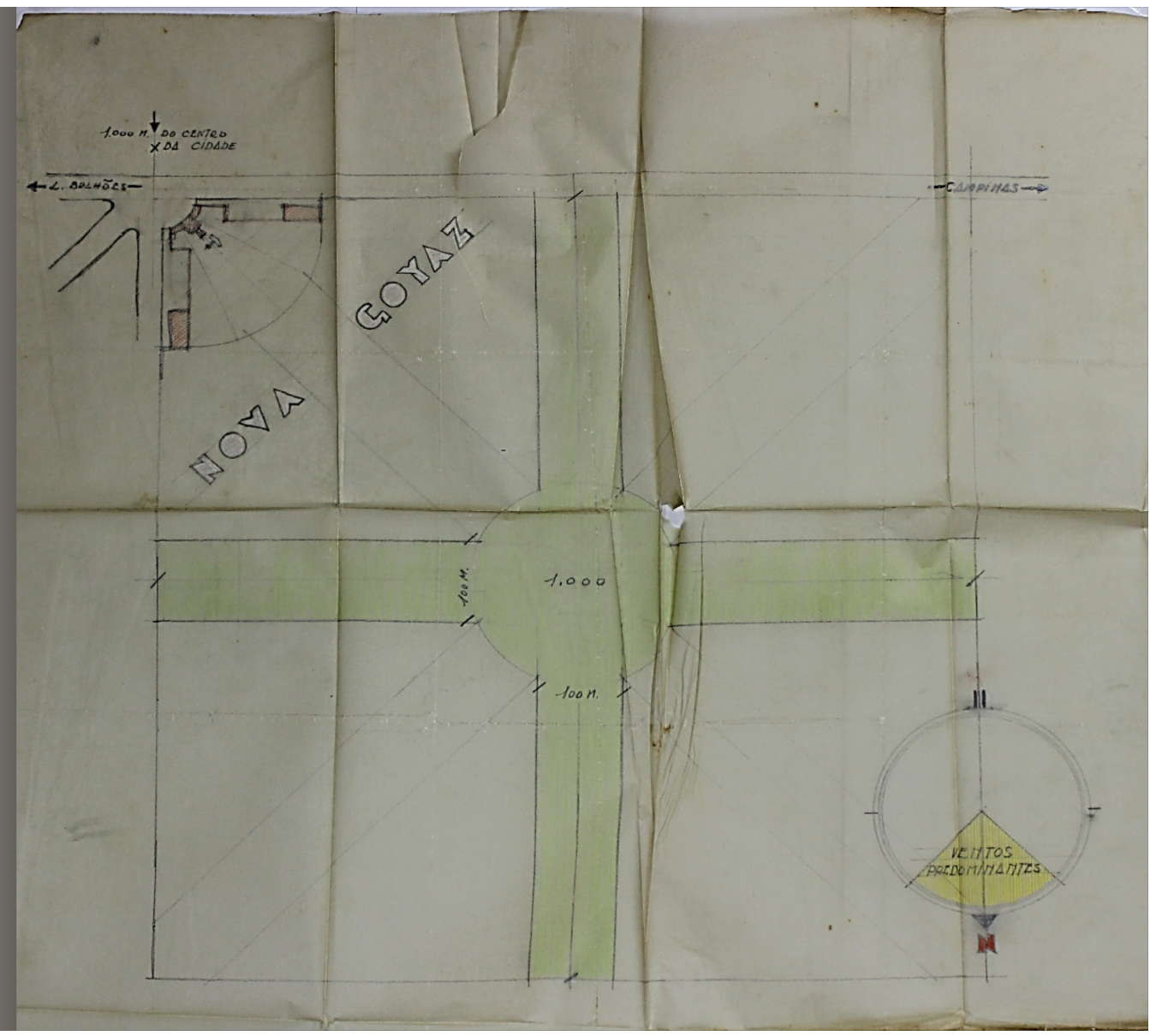

\section{FIGURA 6}

Projeto para as pistas de pouso do Aeródromo de Goiânia. Fonte: acervo da família Corrêa Lima. Foto: Lúcio Malagoni Cardoso. 
Percebe-se na sua exposição o quanto o urbanista preocupou-se e pensou na possibilidade de usar os aviões como meio de transporte para áreas inexploradas no Brasil, como exemplificou no caso de Mato Grosso no final dos anos de 1920. Attilio C. Lima associou o seu trabalho como técnico de motores à arquitetura, sob os aspectos da racionalidade, dialogando com o conceito racionalista do modernismo de Le Corbusier. O novo trabalho foi visto como uma oportunidade para melhorar seus conhecimentos de aspectos da arquitetura que estavam na ordem do dia e que não fizeram parte de sua formação clássica na Escola Nacional de Belas Artes. O mundo das máquinas e motores começava a encantar o arquiteto hábil em desenhar aquarelas e aguadas. Racionalidade, precisão a beleza da máquina estão anunciados no trecho da carta a seguir:

Essa minha passagem por uma usina muito me adiantará, não só para ficar conhecendo bem o motor de explosão, como principalmente por certificar-me de uma coisa que há muitos anos anda bolando da minha cabeça: é que tem se chegado à perfeição em tudo com a racionalização, ao passo que só a arquitetura tem ficado para trás com falsos preconceitos e pontos de vistas falsos. Na construção de um automóvel chega a formas dela pela perfeição e

${ }^{6}$ Carta de Attilio C. Lima para seus pais de 13 de abril de 1929. aperfeiçoamento de todos seus elementos, enquanto na arquitetura já de saída se visa o belo. ${ }^{6}$

Com certeza essa oportunidade única para um arquiteto urbanista em lidar com motores de aviões, com máquinas de voar, inspirou-o a planejar uma capital moderna conectada com o mundo através de um aeroporto e também de uma estação de hidroaviões, como descreve Attilio C. Lima em seu relatório, justificando as ligações da nova capital do Estado de Goiás através das bacias fluviais do Estado:

[...] uma linha de navegação que corte o nosso interior, em busca do Amazonas e dos países da América Central e do Norte, é perfeitamente aceitável. No Estado de Goiás as facilidades são inúmeras. Temos como primeira base o leito do Paranaíba, trezentos quilômetros acima, a represa do Jaó adrede preparada, e finalmente outra etapa semelhante atingindo o curso do Tocantins ou, de preferência o do Araguaia em toda a sua extensão. (LIMA, 1935).

No relatório do Plano Diretor de 1935 entregue ao interventor Pedro Ludovico Teixeira há fotos do "Aeroporto de Goiânia", figura 7, com a legenda: Campo de Campinas - Goyaz, datado em 5 de junho de 1935. As duas fotos aéreas mostram as duas pistas de pouso, tendo no seu perímetro as matas ciliares dos Córregos do Buritys e do Capim-Puba.

\section{FIGURA 7}

\author{
Fotos aéreas \\ do aeroporto \\ de Goiânia - 1937. \\ Fonte: acervo da \\ família Corrêa Lima. \\ Foto - Lúcio Malagoni
} Cardoso

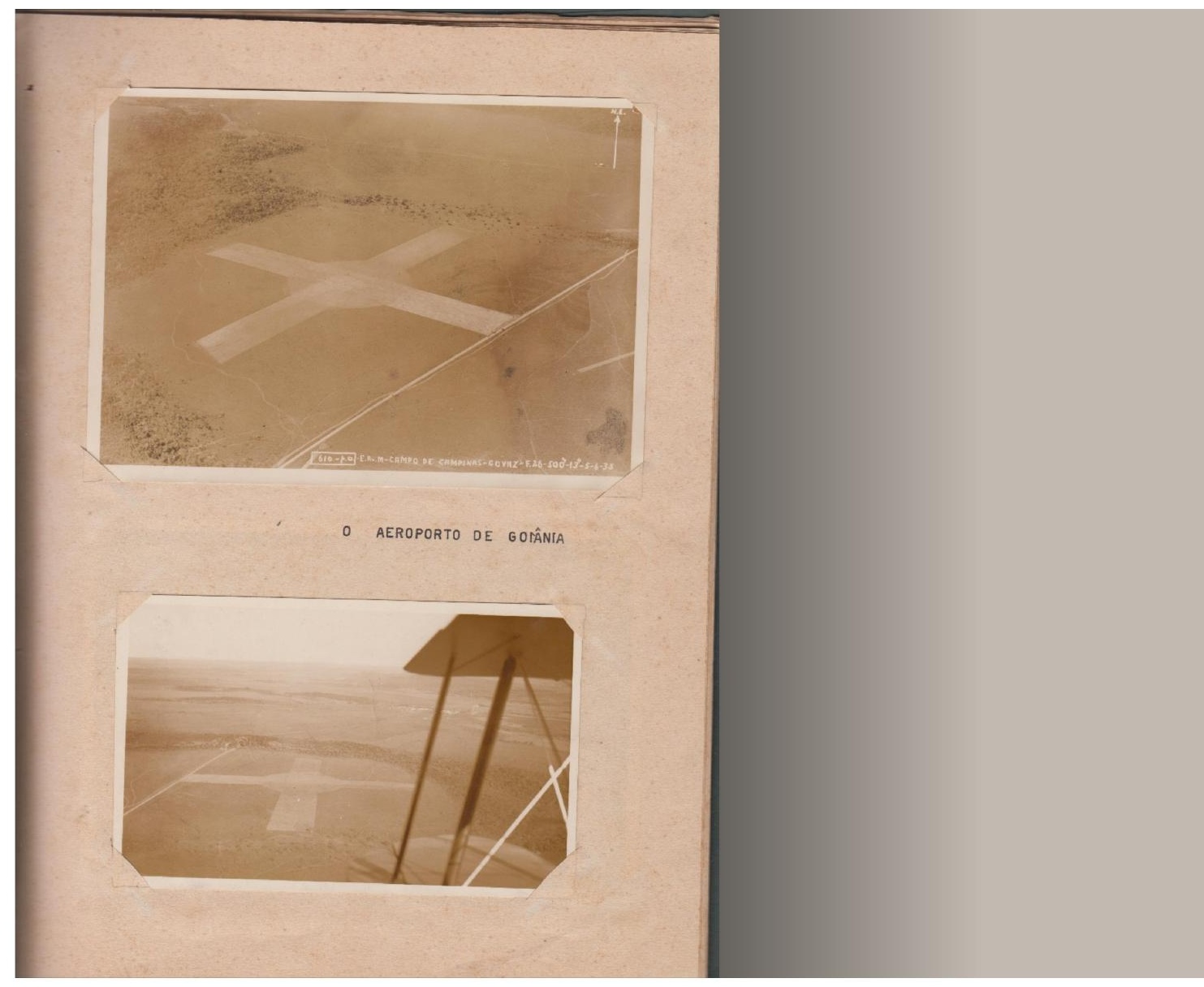




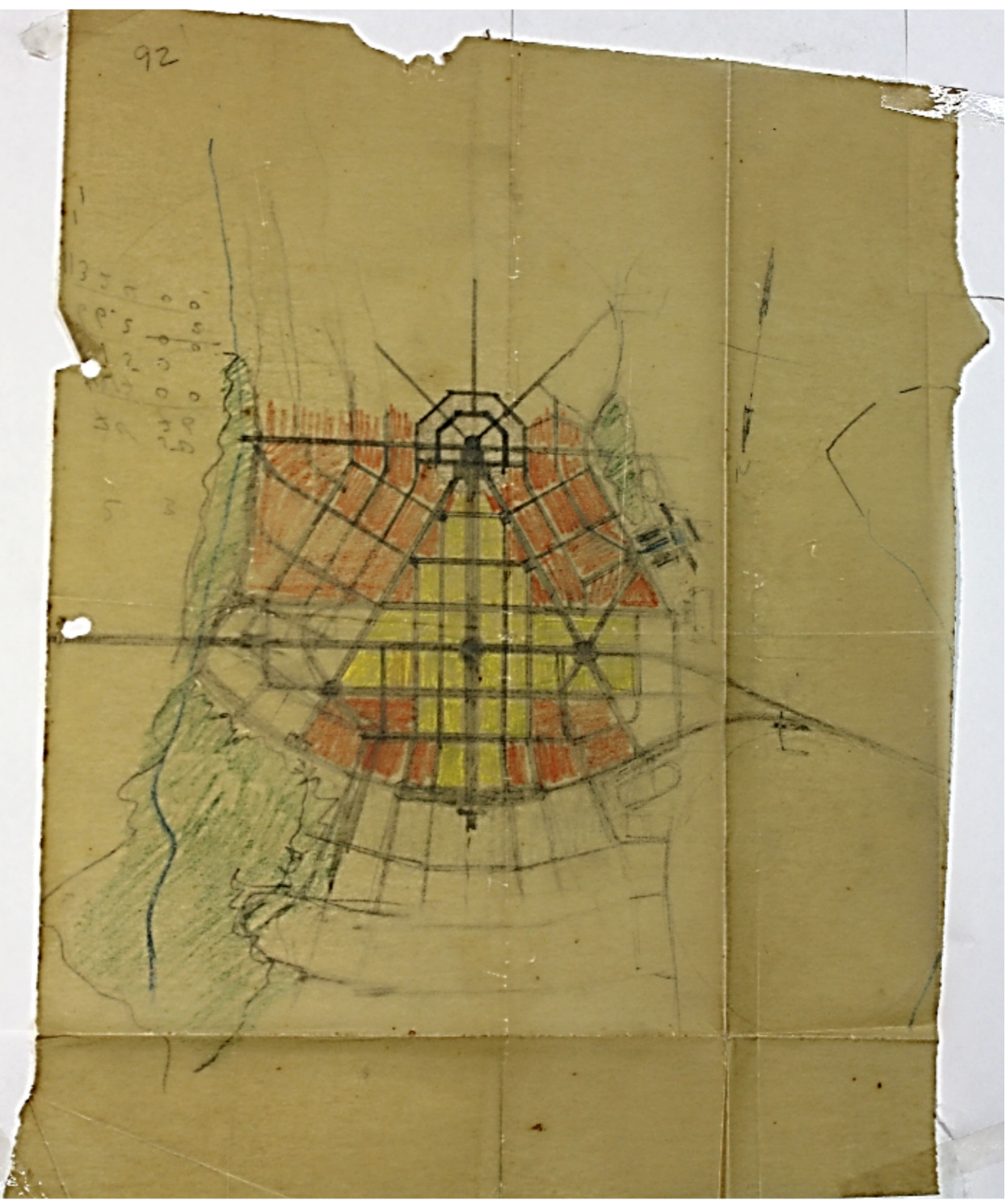

\section{FIGURA 8}

Esboço do

Zoneamento de

Goiânia, 1932.

Fonte: acervo da

família Corrêa Lima.

Foto: Lúcio Malagoni

Cardoso.

As reflexões sobre os motores, as máquinas, o avião e arquitetura moderna serão rebatidas na cidade funcional planeada por Attilio Corrêa Lima - a cidade de Goiânia. O urbanista lançou mão de um dos princípios do urbanismo moderno, preconizados durante o Congresso de Urbanismo em Paris (1928) que ele participou enquanto fazia o curso de urbanismo no IUPP, o "zoneamento", assim detalhou sua intenção:

O zoneamento da cidade é feito procurando satisfazer as tendências modernas, de localizar os diversos elementos da cidade em zonas demarcadas a fim de não só obter a melhor organização dos serviços públicos, como também, para facilitar certos problemas técnicos, econômicos e sanitários, não se falando aqui na estética. (LIMA, 1935).

\section{Goiânia: a cidade funcional}

Attilio Corrêa recebeu um "campo limpo" como ele próprio definiu a área para a implantação da nova capital. A tarefa de criar setores para cada atividade específica foi simples, como o arquiteto reconheceu, "contrário as grandes aglomerações modernas, o zoneamento constitui um problema de fácil solução". Conforme afirmação do arquiteto, a facilidade na resolução não diminui as responsabilidades sobre o plano, "se ele não for rigorosamente obedecido, constituindo um verdadeiro crime a inobservância do que prescreve o regulamento das zonas." Por outro lado Corrêa Lima fez uma ressalva; "é claro que o zoneamento não pode ser levado aos rigores extremos, como querem alguns profissionais, como por exemplo, na zona residencial com as suas múltiplas subdivisões." (LIMA, 1935). 
O urbanista setorizou a cidade em cinco grandes zonas: Administrativa, ao redor da Praça Cívica, Comercial, ao longo da Avenida Pedro Ludovico, Avenidas Araguaia e Tocantins, Industrial, nas quadras abaixo da Avenida Paranaíba, Residencial, urbana na área Leste e Oeste, residencial suburbana na área Sul e Zona Rural.

Na figura 8 um croqui inicial, as áreas pintadas na cor vermelha são as zonas residenciais que Attilio Lima dividiu em duas seções principais: 'A' ou Urbana, e 'B' ou Suburbana "ambas ocupando sempre situações favoráveis e tranquilas, longe dos centros movimentados." (LIMA, 1935). As áreas pintadas na cor amarela correspondiam à zona comercial.

O urbanista salientou sobre a zona residencial a proximidade com as áreas verdes, um dos princípios preconizados posteriormente na Carta de Atenas (1933) para as cidades modernas funcionais:

[...] A zona residencial foi instalada em regiões próximas às áreas de matas, cerradão e veredas, proporcionando tranqüilidade e conforto ambiental, além da facilidade de acesso aos bairros tanto "suburbanos" - Setores Sul e Oeste - como "urbanos" - Setor Central - pelas avenidasparques (Alamedas 115, das Rosas, dos Buritis, do Botafogo e Av. Oeste). Campinas foi planejada como cidade-satélite. (LIMA, 1935)

\section{A ossada de ema e o marco zero da cidade}

Posteriormente, o jornal carioca A Noite noticiou em 4 de julho de 1942 o Batismo Cultural de Goiânia por meio de uma reportagem com o título "Goiânia - a cidade que apareceu no sertão". Assim foi apresentado o urbanista Attilio Corrêa Lima em entrevista:

Realiza-se, amanhã, o "batismo cultural" de Goiânia, a nova capital do Estado de Goiaz, que uma esplêndida realização do governo.

É uma oportunidade para que se ouvisse a palavra do autor do plano da cidade, o conhecido urbanista Correia Lima.

Attilio Correia Lima é um dos nossos mais brilhantes e arrojados urbanistas. Arquiteto pela Escola Nacional de Belas Artes, obteve, em 1926, o prêmio de viagem, e em 1930 regressava ao Brasil, depois de um curso destacado no Instituto de Urbanismo da Universidade de Paris. São de sua autoria os planos de remodelação de Niterói e de Recife, e o plano de edificação de Goiânia. São projetos seus, também, os da transformação do Vale do Paraíba, no trecho que interessa à grande siderurgia e inclui obras de vulto nas cidades de barra Mansa e Volta Redonda e na Vila de Pinheiro. (A NOITE. 4 jul. 1942).
Attilio C. Lima recorda seus primeiros passos para a elaboração dos projetos para a nova capital de Goiás:

Convidado, em 1932, pelo Sr. Pedro Ludovico Teixeira, por intermédio do Sr. Benedito Netto Velasco, naquela ocasião procurador do Estado, fui a Campinas estudar o local e iniciar o projeto da nova cidade. Inúmeras foram as dificuldades que tivemos de vencer, os recursos financeiros eram ínfimos e os métodos de construção ainda primitivos. (A NOITE. 4 jul. 1942).

O urbanista descreve a luta para implantar uma cidade moderna em pleno sertão:

Foi tremenda, realmente, a luta, continua o Sr. Correia Lima. Em pleno sertão deveríamos construir uma cidade. Três fatores deveríamos enfrentar: a dificuldade de obter material - ainda inexplorado na ocasião; o problema da mão-de-obra - deficiente, não adaptada aos métodos modernos de construir - e, finalmente, os transportes para o material vindo de fora. E como se não bastassem as dificuldades acima descritas, tivemos a luta política. De duas maneiras apresentou-se o problema da mudança da capital: a luta aberta desencadeada pela oposição durante o período da propaganda eleitoral e a luta subterrânea da resistência passiva movida pelos interesses prejudicados na mudança do centro vital do Estado. (A NOITE. 4 jul. 1942).

Com o subtítulo da reportagem: Onde o carro de boi é mais útil que o automóvel, Corrêa Lima "descreve, em seguida, com pitoresco e vivo colorido, o seu esforço e o dos seus companheiros de jornada. Fala, quase comovido, das primeiras vitórias":

Felizmente todos os óbices foram vencidos e aí está Goiânia em pleno florescimento. Tanto mais valor tem esse seu desaprochar porque não foi cidade criada com pompa e altos dotes.

Ela se fez desde a primeira edificação, que foi o palácio do governo, através de todas as vicissitudes, à custa ainda do carro de boi dos outros tempos da conquista. Foi esse mesmo carro de boi que nos serviu para movimentar a terra na construção das pistas para o aeroporto da cidade.

Attilio C. Lima emocionado narrou o episódio da chegada do coronel Amilcar Pederneiras como um marco histórico para a nova capital:

Quando o coronel Amilcar Pederneiras, naquela época diretor do Correio Aéreo Militar, por minha solicitação, desceu em Goiânia, se para muitos foi apenas uma novidade do dia, para mim, confesso, foi o dia de maior comoção, pois estava assegurado o futuro da cidade; a aviação resolveria o grande óbice: - a distância; nada impediria o progresso de Goiânia. 


\section{Goiânia - a cidade que apareceu no sertão Uma palestra com $\bullet$ autor do plano da nova capital de Goiaz}

\section{FIGURA 9}

Manchete do jornal

A Noite - 1942.

Fonte: acervo da

família Corrêa Lima.

Concluindo a entrevista Attilio C. Lima falou sobre a felicidade de reencontrar amigos durante os festejos do Batismo Cultural e relembrar a paisagem inicial que encontrou nos primeiros anos de trabalho para implantar a nova capital:

Vou a Goiânia, conclui o urbanista patrício, rever velhos amigos e a cidade mais nova do Brasil, onde sobre suas largas avenidas arborizadas, ainda não faz uma década, pastavam, displicentemente bandos de emas e corvos campeiros. E foi uma ossada de ema que me serviu para localizar o marco Zero da cidade.
No dia seguinte à entrevista ao jornal $A$ Noite, Attilio Corrêa Lima juntamente com sua esposa Olga Fernandes e seu filho Bruno chegam à Goiânia para ser homenageado durante o Batismo Cultural. Panfletos foram distribuídos a população com os dizeres:

Ao Povo - Devendo chegar hoje, às $11 \frac{1}{2}$ horas, pelo avião de carreira da Panair, o grande urbanista Dr. Atílio Correia Lima, autor do plano de construção desta cidade, tenho o prazer de convidar o povo em geral para, em justa homenagem ao ilustre compatrício, ir recebê-lo no aero-porto.

Venerando de Freitas Borges, Prefeito

\section{Ao POD

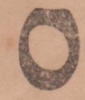

Devendo chegar hoje, às $111 / 2$ horas, pelo avião de carreira da "Panair", o grande urbanista Dr. ATf́LIO CORREIA LIMA, autor do plano de construção desta cidade, tenho o prazer de convidar o povo em geral para, em justa homenagem ao ilustre compatrício, ir recebê-lo no aero-porto.

Venerando de Freitas Borges, Prefeito.

\section{FIGURA 10}

Panfleto - 1942.

Fonte: acervo da família Corrêa Lima. Foto: Lúcio Malagoni Cardoso. 


\section{Idealizando o futuro da nova capital}

Attilio C. Lima apresenta como conclusão do artigo: "Resumo de um Estudo" para a Revista Arquitetura e Urbanismo, em 1937, as funções que a nova capital do estado deveria desempenhar, nos aspectos comercial, industrial, social e administrativo, destacando a sua relevância quanto a localização central, riquezas minerais das regiões próximas e influência que a cidade-capital teria sobre as demais, como um centro moderno de hábitos sociais e estéticos. Assim descreveu o urbanista no que toca a capital geradora de progresso comercial:

Como função econômica cabe-lhe, abrigar e estimular o alto comércio, os estabelecimentos de crédito, e as indústrias. A fixação de um lugar fácil acesso e equidistante das zonas produtoras facilitará a aquisição e a troca, forçando a concentração. Num Estado onde não existem cidades com mais de 10.000 habitantes, a criação de um centro, com seus edifícios públicos, largas avenidas e acondicionamento de todos os requisitos das cidades modernas, inspira confiança e justifica o emprego de capitais. É no apoio consubstanciado pela presença da alta administração estadual, que esta região rica se desenvolverá em progressão geométrica. O destino que a espera é o de ser o maior centro comercial do Estado, pelos recursos de que dispõe. (LIMA, 1937)

Olhando para um futuro promissor da cidade, Corrêa Lima, de forma otimista e nacionalista, lançou a possibilidade de Goiás, um estado rico em minérios, transforma-se em um polo industrial, afirmando:

Sua indústria não será menos importante. Capital de um dos Estados mais ricos em minérios, poderá ser um centro metalúrgico quando nos libertarmos dos mercados estrangeiros. O nosso ferro e o nosso níquel que se evadem para o exterior, voltando como maquinismos por preços astronômicos, poderão, quem sabe, ser ali mesmo transformados. No dia em que se desfizer a lenda insuflada de fora, e que diz ser o Brasil um país essencialmente agrícola; e que ativarmos a nossa indústria, qual será o papel que desempenhará está cidade? (LIMA, 1937)

Quanto ao desempenho administrativo da capital, o arquiteto urbanista foi enfático e reforçou os aspectos de centralização das decisões, porém sendo um modelo de vanguarda influenciando outras cidades, descreveu então:

[...] Como centro administrativo cabe-lhe a função de cabeça e de orientador. Sua política administra sempre vigilante, será o coordenador e o estimulante para as atividades econômicas e sociais. Sua posição deverá ser sempre na vanguarda, como tipo modelar, a sua estrutura urbana deve ser ampla, refletindo uma certa nobresa de linhas quer no seu traçado, quer na sua edificação. Cabe a administração a suma responsabilidade de velar rigorosamente, pela aplicação dos regulamentos, evitando sempre as concessões de qualquer espécie, que possam desmerecer a dignidade de uma capital.
O rigor das medidas nela aplicadas será exemplo que despertará as outras aglomerações urbanas do seu letargo. Goiânia não vale somente pelo seu valor intrínseco, mas principalmente pela influência que poderá exercer.

Finalizou o artigo com olhos no futuro de Goiânia, como uma cidade mãe, uma metrópole, com muita propriedade encerrou anunciando: " [...] num país ou num Estado, a capital é sempre o padrão, onde os outros satélites se espelham, por isso designavam os antigos de "METROPOLE". (LIMA, 1937)

\section{Considerações finais}

Goiânia em suas primeiras décadas de concepção e implantação de seu plano, foi marcada por fragmentações de diferentes traçados e influências urbanísticas. Originalmente pelo traço do urbanista Attilio Corrêa Lima, quase que simultaneamente pelas intervenções especulativas dos engenheiros Coimbra Bueno, assessorados por Armando de Godoi, e posteriormente pelo topógrafo Ewald Janssen.

Há várias lacunas não abordadas na histografia da cidade principalmente sobre a concepção original do plano diretor de Attilio Corrêa Lima de 1935. Plano esse não reconhecido, uma vez que os Coimbra Bueno logo após a saída de Attilio C. Lima à frente da elaboração dos projetos urbanísticos e das obras, alteraram consideravelmente a concepção inicial do plano para a nova capital.

Para o engenheiro Abelardo Coimbra Bueno, irmão de Jeronimo Coimbra Bueno, teórico da "civilização sertaneja" e sócio da empresa que construiu Goiânia " a ideia fundamental nossa, nascida em Goiânia, era que nós devíamos criar um polo de desenvolvimento da civilização brasileira", mas para isso o engenheiro argumenta que:

[...] devia mudar o governo, pra mudar a mentalidade e começamos até, naquela época, o que nós chamamos "a campanha da civilização sertaneja". Que deveria esta, esse, essa idéia de um desenvolvimento do interior, para contrabalançar a civilização costeira, que era predominante, naquela época ainda no Brasil. Nós vivíamos assim, numa civilização colonial, esse tempo todo era de características colonialistas. Então precisava criar uma outra no interior para então a idéia, quando as duas tivessem já desenvolvidas, quer dizer, a do interior tivesse desenvolvida, nós então fundiríamos para criar a idéia de civilização brasileira (SILVA, 1997:39).

A imagem (FIGURA 11) que mais exemplifica a campanha da civilização sertaneja, a dualidade entre modernidade e passado, é a construção da capital utilizando a força do carro de boi para asfaltar as ruas e avenidas da nova capital. 


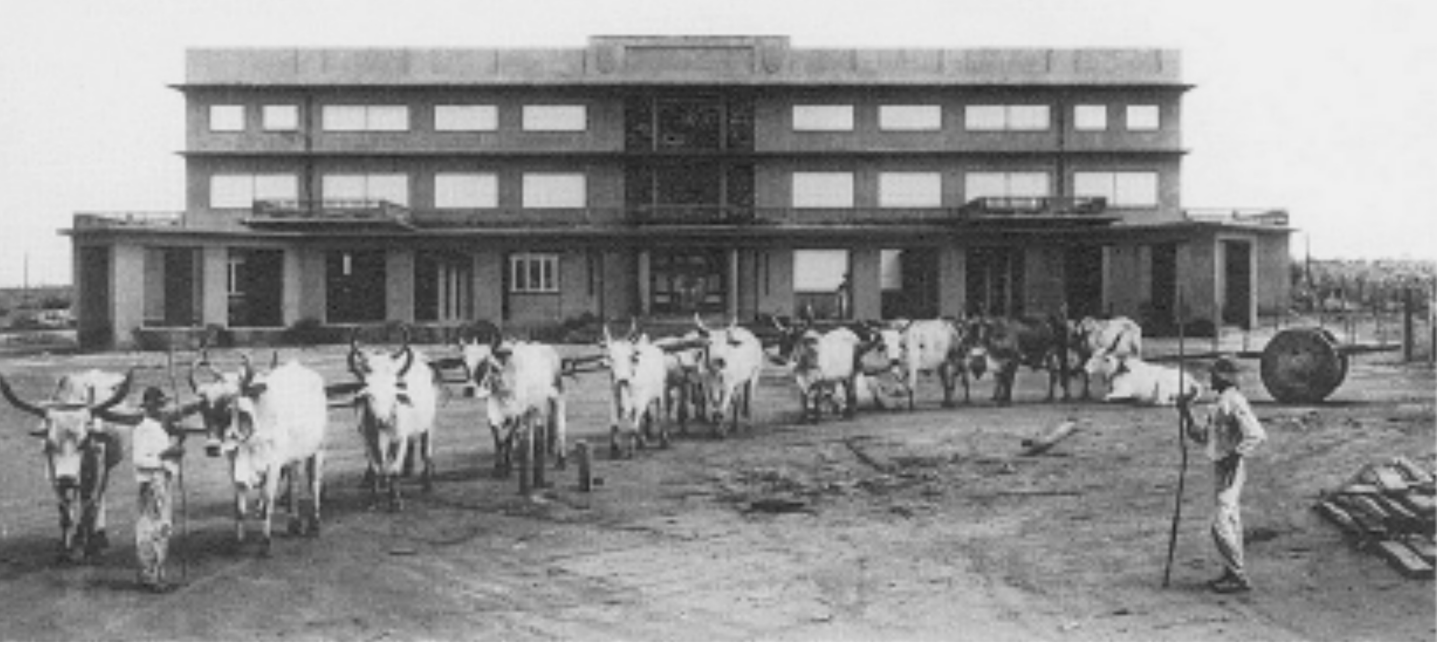

\section{FIGURA 11}

Carro de boi construindo a cidade moderna no sertão. Fonte: SEPLAN.
A construção do "moderno no sertão", materializada na implantação da nova capital do Estado de Goiás, no nada, com a destruição da paisagem original do cerrado, vai de encontro da modernidade idealizada num cenário artificial projetado, querendo negar o passado colonial da antiga Cidade de Goiás e mascarando as práticas políticas e sociais que se mantiveram. Uma dialética entre espaço e forma da cidade moderna como estruturas de superfície e o velho querendo ser "novo".

\section{Referências Bibliográficas}

BORGES, Lindsay. Revista da Arquidiocese de Goiânia (1957-1967): as representações e a construção da unidade religiosa. Dissertação de Mestrado (UFG - Goiás) 2007.

BORTOLUCI, José Henrique. Para além das Múltiplas Modernidades: Eurocentrismo, Modernidade e as Sociedades Periféricas. São Paulo, 2009. Plural - Revista do Programa de Pós-graduação em Sociologia USP.

DINIZ, Anamaria. Goiânia de Attilio Corrêa Lima (19321935), ideal estético e realidade política. Dissertação de Mestrado (UnB - Brasília) 2007.

O itinerário pioneiro do urbanista Attilio Corrêa Lima. Tese de Doutorado (UnB - Brasília) 2015.
LANDER, Edgardo. "Ciências sociais: saberes coloniais e eurocéntricos" in Lander (org). Colección Sur Sur, CLACSO. Ciudad Autónoma de Buenos Aires, Argentina, setembro 2005, pp. 21-53.

Lima, Attílio Corrêa. "Goiânia, a nova capital de Goiás" in Arquitetura e Urbanismo, jan. /fev. 1937, p. 32-34.

"Goiânia, a nova capital de Goiás (cont.)" in Arquitetura e Urbanismo, mar. /abr. 1937, p. 60-63.

"Goiânia, a nova capital de Goiás (cont.)" in Arquitetura e Urbanismo, mai/jun. 1937, p. 140-146.

Goiânia, a nova capital de Goiás: resumo de um estudo in IBGE. Goiânia / Rio de Janeiro: Serviço Gráfico, 1942.

MELLO, Márcia Metran. Goiânia: Cidade de Pedra e de Palavras. Tese de Doutorado (UnB - Brasília) 2004.

MENDONÇA, Jales G. Coelho. "A queda de Bonfim e a escolha prévia de Campinas" in Revista Mosaico, v. 2, 2009, pp. 175-189.

MONTEIRO, Ofélia Sócrates do Nascimento. Como nasceu Goiânia. São Paulo: Revista dos Tribunais, 1938.

SILVA, Luiz Sérgio Duarte. A Construção de Brasília: modernidade e periferia. Goiânia: Editora UFG, 1997. 